CAmerican Psychological Association, 2020. This paper is not the copy of record and may not exactly replicate the authoritative document published in the APA journal. Please do not copy or cite without author's permission. The final article is available, upon publication, at: 10.1037/com0000259

Accepted for publication $23^{\text {rd }}$ September 2020 in the Journal of Comparative Psychology.

\title{
Personality Structure in Bottlenose Dolphins (Tursiops truncatus)
}

F. Blake Morton ${ }^{1}$, Lauren M. Robinson ${ }^{2,3}$, Sabrina Brando ${ }^{4,5}$, Alexander Weiss ${ }^{6,7}$

${ }^{1}$ Department of Psychology, University of Hull

${ }^{2}$ Domestication Lab, Konrad Lorenz Institute of Ethology, University of Veterinary Medicine Vienna

${ }^{3}$ Department of Psychology, Georgia State University

${ }^{4}$ AnimalConcepts

${ }^{5}$ Psychology, University of Stirling

${ }^{6}$ Department of Psychology, School of Philosophy, Psychology and Language Sciences, The University of Edinburgh

${ }^{7}$ Wildlife Research Center, Kyoto University

\section{Author Note}

F. Blake Morton ? https://orcid.org/0000-0002-8644-1557

Lauren M. Robinson ? https://orcid.org/0000-0001-8490-3423

Sabrina Brando ?? https://orcid.org/0000-0002-4283-3444

Alexander Weiss ? https://orcid.org/0000-0002-9125-1555

We have no known conflicts of interest to declare.

We are grateful to the participating facilities, and especially staff from the Dolphin Research Center, for providing ratings and logistical support. Special thanks go to Mandy Rodriguez, Fabienne Delfour, Edgar Urbina, Alejandro Mata, Kim Terrell, Niels van Elk, and 
Pernilla Mosesson for logistical support, and to Chloe Weatherill for translating the questionnaire into Spanish. Collection of data from Curaçao was partly funded by an honorarium awarded to Alexander Weiss by the Association for the Study of Animal Behavior, and funding by Geoff Hosey and Sabrina Brando through AnimalConcepts. Finally, we thank Colin DeYoung and the anonymous reviewers for their helpful comments.

Correspondence concerning this article should be addressed to Dr Blake Morton, Department of Psychology, University of Hull, Hull, HU6 7RX, United Kingdom. E-mail: b.morton@hull.ac.uk. 


\section{Abstract}

2 Comparative studies can help identify selective pressures that contributed to species

3 differences in the number and composition of personality domains. Despite being adapted to

4 an aquatic lifestyle and last sharing a common ancestor with primates some 95 million years

5 ago, bottlenose dolphins (Tursiops truncatus) resemble nonhuman primate species in several

6 behavioral and cognitive traits. For example, like chimpanzees (Pan troglodytes), dolphins

7 live in fission-fusion societies, use tools, and have relatively large brains. To determine the

8 extent to which these and other factors contribute to the evolution of personality structure, we

9 examined personality structure in 134 bottlenose dolphins. Personality was measured in 49

10 dolphins using a 42-item questionnaire, and in 85 dolphins using a version of the

11 questionnaire that included 7 additional items. We found four domains. Three-openness,

12 sociability, and disagreeableness - resembled personality domains found in nonhuman

13 primates and other species. The fourth, directedness, was a blend of high conscientiousness

14 and low neuroticism, and was unique to dolphins. Unlike other species, dolphins did not

15 appear to have a strong dominance domain. The overlap in personality structure between

16 dolphins and other species suggests that selective pressures, such as those related to group

17 structure, terrestrial lifestyles, morphology, and social learning or tool use are not necessary

18 for particular domains to evolve within a species. 


\section{Introduction}

An ongoing goal of personality research is to understand the evolutionary origins of personality structure, that is, the number and composition of personality domains, in humans and other animals (Gosling \& Graybeal, 2007; Weiss, 2018). Work in humans has shown that personality structure arises from genetic correlations between personality traits (McCrae et al., 2001; Rowe, 1982; Yamagata et al., 2006), and that individual differences in personality traits are associated with fitness-related outcomes, including reproduction (Alvergne et al., 2010; Gurven et al., 2014; Jokela et al., 2011), health, and longevity (Strickhouser et al., 2017). However, although these findings indicate that natural selection may play a role in the evolution of personality structure, it is unclear what selective pressure or pressures led to species similarities and differences in personality structure.

One set of findings that has provided insight into the evolution of personality structure concerns dominance. Broad personality factors or components related to dominance are found in many nonhuman primate species (see Freeman \& Gosling, 2010 for a review). In humans, however, dominance tends to be found at lower levels of personality organization, such as the facet level (Costa \& McCrae, 1995). These findings may reflect the fact that, unlike humans who have more egalitarian social structures (Boehm, 1999; von Rueden, 2020), many nonhuman primate species form linear hierarchies (Bernstein, 1981; CluttonBrock \& Huchard, 2013; Cowlishaw \& Dunbar, 1991; de Ruiter \& van Hooff, 1993; Fedigan, 1983; Isbell, 1991; Wittig \& Boesch, 2003). In support of this explanation, a study of six macaque species (genus Macaca) found that the makeup of personality domains related to social competence and aggression were related to the degree to which the social style of a species was despotic (Adams et al., 2015).

To take another example, conscientiousness, which describes the extent to which individuals pay attention to detail, are diligent, and are self-disciplined, is found at the 
44

45

46

47

48

49

50

51

52

53

54

55

56

57

58

59

60

61

62

63

64

65

66

domain level in humans (Digman, 1990), but similar domains have not been found in all primate species. To date, the only nonhuman primate species that appear to possess a conscientiousness domain include chimpanzees Pan troglodytes (e.g., King \& Figueredo, 1997) and bonobos Pan paniscus (Weiss et al., 2015), both of which are closely related to humans (Glazko \& Nei, 2003), and two New World monkey species, namely brown capuchin monkeys Sapajus apella (Morton et al., 2013) and common marmosets Callithrix jacchus (Iwanicki \& Lehmann, 2015; Koski et al., 2017) ${ }^{1}$ that are distantly related to humans, chimpanzees, and bonobos (Glazko \& Nei, 2003).

Humans, chimpanzees, bonobos, and brown capuchin monkeys typically learn to use tools by watching and practicing in the presence of other individuals using tools, and these other individuals are often the focus of the novices' (visual) attention (Coelho et al., 2015; Deák, 2014; Fragaszy et al., 2017; Nagell et al., 1993; van Schaik et al., 1999; Whiten \& van de Waal, 2018). Common marmosets, however, do not use tools, but males and females of this species care for the offspring of other group members; that is, they engage in cooperative breeding (Burkart et al., 2014), which humans may also do (Hrdy, 2009). Thus, factors related to tool use (e.g., being attentive towards a demonstrator) and/or cooperative breeding (e.g., being attentive towards an infant) may be routes by which conscientiousness evolved in humans and these nonhuman primate species.

Comparative studies with other terrestrial vertebrates also contribute to our understanding of personality structure evolution. For example, horse (Equus caballus) personality includes a domain that appears to be a blend of extraversion and agreeableness (Lloyd et al., 2008). Similar domains have been found in Virunga mountain gorillas Gorilla gorilla beringei (Eckardt et al., 2015), brown capuchin monkeys (Morton et al., 2013), and

\footnotetext{
${ }^{1}$ A third study of common marmosets by Inoue-Murayama et al. (2018) did not find a conscientiousness domain, although that does not appear to be the last word for that sample (Weiss et al., 2020).
} 
macaques (Adams et al., 2015; Brent et al., 2014; Capitanio, 1999; Figueredo et al., 1995;

Konečná et al., 2012; Neumann et al., 2013; Rouff et al., 2005; Stevenson-Hinde \& Zunz, 1978; Uher et al., 2013; Weiss et al., 2011). Horses, like the aforementioned primate species (Shultz et al., 2011), live in stable groups (McCort, 1984) and form long-term bonds (Cameron et al., 2009). However, unlike these primate species (Byrne \& Whiten, 1988; Hall \& Brosnan, 2017; Wheeler, 2009), horses do not engage in behaviors related to tactical deception (Krueger, 2008). Thus, affiliative or other prosocial behaviors may have played a greater role than tactical deception in the evolution of personality domains that are blends of extraversion and agreeableness.

Although comparative studies offer a promising method to help understand how personality structure evolved, they have been largely limited to vertebrates with exclusively terrestrial lifestyles. As a consequence, it is too soon to exclude the possibility that factors related to living on land, such as habitat types, locomotion, physical anatomy, diet, and how individuals communicate, are responsible for similarities in personality structure. The importance of studying personality in species adapted to non-terrestrial environments is highlighted by recent studies of marine mammals. Ciardelli et al. (2017) found, for example, an extraversion/impulsivity and dominance/confidence domain in California sea lions (Zalophus californianus), which resembled domains found in species that are exclusively terrestrial. Ciardelli et al. also found a reactivity/undependability domain, which resembled the human-directed agreeableness domain that Gosling (1998) found in spotted hyenas (Crocuta crocuta). In another study, Úbeda et al. (2019) found three domains-extraversion, dominance, and "conscien-agreeableness"-in orcas (Orcinus orca), which resembled the domains found in California sea lions, ${ }^{2}$ and a fourth domain, careful, that was not found in

\footnotetext{
${ }^{2}$ Conscien-agreeableness, like human-directed agreeableness, appeared to be reflected
} versions of reactivity/undependability. 
90 California sea lions or in terrestrial mammals. Together, these studies of marine mammals

suggest that personality domains like dominance, extraversion, and reactivity/undependability evolved in response to selective pressures other than those related to living on land, and that the evolution of the domain careful may have been attributable to selective pressures unique to orcas or, perhaps, cetaceans in general.

To extend work on non-terrestrial animals, we obtained data using a personality rating scale designed for another cetacean species, the bottlenose dolphin (Tursiops truncatus). Although prior studies of bottlenose dolphins have not examined personality structure, they have demonstrated that observer ratings are stable across time, show satisfactory levels of interobserver agreement (Highfill \& Kuczaj, 2007), and are correlated with data from behavioral codings (Moreno et al., 2017) and social network centrality (Díaz López, 2020). The second aim of our study was to better understand what evolutionary factors contributed to species variation in personality structure. To do this, we compared the structure of bottlenose dolphins to those reported in primates and other species. Unlike primates, for example, dolphins spend most of their lives underwater (Hastie et al., 2003), lack hands for object manipulation, have a diet that consists mainly of fish (Walker et al., 1999), and use echolocation to forage, explore, and navigate their environment (Au, 1993). However, despite these and other differences, and last sharing a common ancestor with primates some 95 million years ago (Kumar \& Hedges, 1998), dolphins share several behavioral and cognitive traits with primates, including great apes. Dolphins, for example, form complex social bonds (Lusseau et al., 2006; Moreno \& Acevedo-Gutiérrez, 2016), use tools and display cultural traditions (Krützen et al., 2005), engage in prosocial behavior (Nakahara et al., 2017), possess cognitive abilities related to imitation, cooperation, and vocal recognition (Bruck, 2013; Jaakkola et al., 2018; Jaakkola et al., 2010), have non-conceptive sex (Furuichi et al., 2013), and engage in sexual coercion and Machiavellian behavior 
115 (Kuczaj et al., 2001; Wallen et al., 2016). Thus, overlapping dolphin and primate personality structures would suggest that characteristics of primates that are not shared with dolphins

117 (e.g. morphology, diet, terrestrial lifestyles, and sensory perception) are not necessary for 118 such personality domains to evolve, and that the characteristics that primates share with 119 dolphins played a greater role.

\section{Method}

Ethics

This and similar studies were declared to be exempt from review by the Research Ethics Committee of the University of Edinburgh. The dolphin facilities were accredited by relevant authorities (IMATA, EAAM, and WAZA) and complied with the ethical guidelines of those authorities as well as local legislation.

\section{Subjects} female. Age data were not available for two females. Of the 132 other dolphins, age ranged from 2 to 52 years and the mean age was 16.8 years $(S D=10.6)$. In males, age ranged from 2 to 40 years and the mean age was 14.2 years $(S D=11.0)$. In females, age ranged from 4 to 52 years and the mean age was 18.8 years $(S D=9.9)$. countries: 7 from Dolphin Discovery in Mexico (Six Flags, Costa Maya, Los Cabos, Isla

134 Mujeres, Cozumel, Vallarata, and Puerto Aventuras) housed 20 males and 37 females, 2 135 facilities in France (Parc Astérix and Planète Sauvage) housed 8 males and 7 females, the 136 Dolphin Research Center in the United States housed 7 males and 9 females, Dolphin 137 Academy in Curaçao housed 2 males and 5 females, Dolfinarium in the Netherlands housed 6 138 males and 5 females, Kolmården in Sweden housed 2 males and 6 females, Dolphin 139 Encounters in the Bahamas housed 6 males and 7 females, and Dolphin Discovery in the 
140 Cayman Islands housed 4 males and 3 females. Visitors could touch and/or swim with

141 dolphins at all facilities except for Parc Astérix and Planète Sauvage.

\section{Questionnaire}

Dolphins were rated on the Dolphin Personality Questionnaire (see supplementary materials). Printed instructions asked raters to indicate on a 5-point scale the extent to which each item was characteristic of the dolphin $(1=$ very uncharacteristic to $5=$ very

characteristic). The instructions also asked raters to not discuss their ratings among themselves or with others.

The questionnaire included 49 items adopted from primate personality questionnaires (King \& Figueredo, 1997; Stevenson-Hinde \& Zunz, 1978; Weiss et al., 2009) judged to be relevant to dolphin personality based on a consensus from staff at the Dolphin Research Center who had many years of experience working with dolphins. Each item consisted of a trait label followed by one or more sentences describing the item in the context of dolphin behavior. For example, the descriptor for "Exhibitionistic, flamboyant" was "Behaves as if deliberately trying to attract attention." A dolphin that scored high on this item might, for example, try to attract attention from visitors or staff as they walk past their aquarium by blowing bubbles or making noises from their blow hole until the human looks at them. "Aggressive". Another type consisted of a pair of adjectives, for example "Active, energetic". A third type consisted of two versions of single trait adjectives with one version referring to the trait in the context of interactions with dolphins, for example, "Sociable (with dolphins)", and one version referring to the trait in the context of interactions with people, for example, "Sociable (with people)". The fourth type consisted of two versions of adjective pairs, with one version referring to the trait in the context of interactions with dolphins and another referring to the trait in the context of interactions with people. 
165

166

167

168

169

170

171

172

173

174

175

176

177

178

179

180

181

182

183

184

185

186

187

188

189

\section{Raters and Ratings}

There were 82 raters. Raters were staff members who agreed to participate in the study, knew the dolphins that they rated for at least one year, and had observed these dolphins in various contexts (e.g., feeding, training, and visitor swimming programs). Raters from facilities in Mexico completed questionnaires that were translated into Spanish by a native English speaker who was fluent in Spanish and then back-translated by a native Spanish speaker who was fluent in English. All other raters completed the English-language version of the questionnaire. Each rater rated between 1 and 16 dolphins (mean $=6.7, S D=5.8$ ). One hundred and three dolphins were rated on all 49 items. In addition, due to a clerical error, 31 dolphins - 16 at the Dolphin Research Center, 8 at Kolmården, and 7 at the Dolphin Academy — were rated on only 42 of the items. In 2012 (6 years after being assessed on the 42 items) the dolphins at the Dolphin Research Center were rated on the 7 additional items. However, because we did not want to introduce method variance into our data, we omitted ratings of these dolphins on those seven items. Each of the 134 dolphins was rated by between 1 and 13 raters (mean $=4.1, S D=3.5)$.

\section{Analyses}

We used R version 3.6.3 (R Core Team, 2020) to conduct our analyses. Unless otherwise specified, all functions were from version 1.9.12 of the psych package (Revelle, 2019).

\section{Missing Data}

We received 548 completed questionnaires. For the 230 ratings of the 31 dolphins rated on the 42-item questionnaire, there were a total of 9660 possible ratings and no missing data. For the 318 ratings of the 103 dolphins who were rated on the 49-item questionnaire, there were a total of 15,582 possible ratings of items. Of these possible ratings, 560 responses were left blank: 1 item was left blank on 39 questionnaires, 2 were left blank on 14 
190

191

192

193

194

195

196

197

198

199

200

201

202

203

204

205

206

207

208

209

210

211

212

213

questionnaires, 3 were left blank on 3 questionnaires, 5 were left blank on 8 questionnaires, 7 were left blank on 35 questionnaires, 8 were left blank on 11 questionnaires, 10 were left blank on 2 questionnaires, 11 were left blank on 1 questionnaire, 15 were left blank on 3 questionnaires, and 35 were left blank on 1 questionnaire.

We omitted seven questionnaires in which raters left more than one sixth (nine or more) of the questions blank (cf. Costa \& McCrae, 1992; Morton et al., 2013). This cut-point corresponded to the number of missing items that exceeded the $95^{\text {th }}$ percentile. After excluding these ratings, we were left with 230 ratings of the 31 dolphins rated on the 42 -item questionnaire and 311 ratings of the 103 dolphins rated on the 49 -item questionnaire. We replaced the remaining missing ratings in these data with the mean rating for that item across all non-missing data. Similar methods for handling missing data have yielded correlation matrices similar to those obtained using alternative methods (see, e.g., Costa et al., 1985).

\section{Interrater Reliabilities of Items}

For dolphins that had been rated by at least two raters, we used a custom function to calculate two intraclass correlation coefficients (Shrout \& Fleiss, 1979) for each of the 49 items. The first intraclass correlation coefficient, $\operatorname{ICC}(3,1)$, indicates the reliability of single ratings. The second, $\operatorname{ICC}(3, k)$, indicates the reliability of the mean scores across $k$ raters.

\section{Exploratory Factor Analysis}

Our factor analyses were based on the mean scores for each trait across raters per dolphin. We followed procedures used in other studies of nonhuman primates (e.g., Weiss et al., 2015), which have been described in Weiss (2017). However, we were forced to deviate from this approach in two ways. First, based on earlier analyses, we included an additional test to determine the number of factors. Second, the results of our initial factor analysis led us to conduct two pre-registered factor analyses. 
Our initial factor analysis was based on a correlation matrix obtained from data on all

215

216

217

218

219

220

221

222

223

224

225

226

134 dolphins on all 49 questionnaire items. Because 31 dolphins were not rated on the 7

additional items, we used the corFiml function to obtain the full information maximum

likelihood correlation matrix.

Simulation studies indicate that the sample size required for exploratory factor analysis depends on the communalities, that is, the proportion of the variance in each item that is explained by the factors, the number of items, and the number of factors (de Winter et al., 2009; MacCallum et al., 1999; Mundfrom et al., 2005). Similar studies of nonhuman primates have typically found a wide range of item communalities and anywhere from three to six factors. For example, a study of bonobos that were rated on 54 items found item communalities that ranged from .14 to .82 and six factors (Weiss et al., 2015). Based on the aforementioned simulation studies, we determined that, depending on the number of factors, we would need 60 to 100 subjects. The present sample size should thus be adequate.

To determine how many factors to extract, we conducted parallel analyses (Horn, 1965) using the fa.parallel function. Because a recent simulation study showed that parallel analysis is more likely to recover the correct number of factors when it tests for the number of eigenvalues from principle components that exceed the $95^{\text {th }}$ percentile of 1000 sets of eigenvalues from simulated data (Auerswald \& Moshagen, 2019), we examined the results for components. We then used the VSS function to determine the number of factors that led to the lowest Bayesian Information Criterion (BIC; Schwarz, 1978). We judged the degree of evidence against there being no difference between the lowest BIC and the next lowest BIC using criteria described in the second table on page 777 of Kass and Raftery (1995). Specifically, differences in BIC that were equal to or exceeded 2 were evidence against the null hypothesis that the solution with fewer factors did not differ in fit from a solution with more factors. Finally, we checked the scree plots. 
After determining the likely number of factors, we used maximum likelihood factor

analysis to extract factors and subjected these factors to an orthogonal (varimax) and oblique

241 (promax) rotation. If the oblique rotation yielded factors that differed in their meaning from

242 the varimax-rotated factors, or factors that were highly correlated, we interpreted these

243 factors. Otherwise, we interpreted the varimax-rotated factors.

As in previous studies (e.g., Weiss et al., 2015), for interpreting factors, we defined

salient loadings as those equal to or greater than |.4|. When labeling factors, to the extent that

it was possible, we used labels from the human and animal personality literature. As such, if a factor resembled a five-factor model domain or facet (Costa \& McCrae, 1995), or a domain found in multiple species, such as dominance (Freeman \& Gosling, 2010), we assigned this factor the same label. In cases where factors appeared to be a blend of two or more domains, we based our label on comparable human personality styles (Costa \& McCrae, 1998) or types (Vollrath \& Torgersen, 2002). In all cases, these labels should be considered tentative until future studies establish the nomological network of the factors (Cronbach \& Meehl, 1955). We preregistered two of our factor analyses (10.17605/OSF.IO/3CWJE) with the Open Science Foundation website (https://osf.io/3cwje). We conducted these analyses to address the importance of considering an item's context when analyzing dolphin personality ratings (Kuczaj et al., 2012). As such, for the first pre-registered analysis we excluded items that referred to "people" and in the second we excluded items that referred to "dolphins".

258 Each pre-registered analysis was therefore based on 42 items. Based on the results of 259 simulation studies described earlier, we determined that, depending on the number of factors, we would need from 60 to 130 subjects. We used the same approach as in our initial analyses to determine the number of factors and to extract, rotate, interpret, and label the factors. 
To determine the interrater reliabilities of individual ratings and mean ratings for our

264 factors, we computed unit-weighted factor scores (Gorsuch, 1983) by assigning each item to

265 a factor. Items were assigned to a factor if they had the highest salient loading on a factor. We

266 then assigned a weight of $+1,-1$, or 0 to each loading depending on whether the loading was

267 salient and positive, salient and negative, or not salient, respectively. We used the alpha

268 function to obtain internal consistency reliabilities (Cronbach's alphas) for each factor based

269 on the items that made up the factor score.

270

\section{Results}

\section{Interrater Reliabilities of Items}

All of the interrater reliabilities were greater than zero (see Table 1). Therefore,

273 consistent with previous studies (e.g., Weiss et al., 2015), we did not exclude any items from

274 further analyses.

275 Table 1

Interrater Reliabilities of the 49 Items

\begin{tabular}{|c|c|c|}
\hline Item & $\operatorname{ICC}(3,1)$ & $\operatorname{ICC}(3, k)$ \\
\hline Dominant $^{\mathrm{a}}$ & .59 & .87 \\
\hline Active, energetic ${ }^{a}$ & .56 & .85 \\
\hline Submissive $^{\mathrm{a}}$ & .53 & .83 \\
\hline Intelligent $^{\mathrm{a}}$ & .52 & .83 \\
\hline Distractible $^{b}$ & .50 & .76 \\
\hline Playful ${ }^{a}$ & .49 & .81 \\
\hline Temperamental $^{\mathrm{a}}$ & .49 & .81 \\
\hline Friendly (to people) ${ }^{a}$ & .48 & .81 \\
\hline Clumsy $^{\mathrm{a}}$ & .48 & .75 \\
\hline Jealous $^{\text {a }}$ & .47 & .80 \\
\hline Cunning $^{\text {a }}$ & .45 & .79 \\
\hline Fearful, nervous ${ }^{\text {a }}$ & .45 & .78 \\
\hline $\operatorname{Lazy}^{\mathrm{a}}$ & .45 & .78 \\
\hline Suspicious ${ }^{\text {a }}$ & .45 & .79 \\
\hline Bold, brave ${ }^{a}$ & .44 & .78 \\
\hline Erratic $^{a}$ & .44 & .78 \\
\hline Exhibitionistic, flamboyant ${ }^{a}$ & .43 & .78 \\
\hline Stubborn $^{a}$ & .43 & .77 \\
\hline
\end{tabular}




\begin{tabular}{|c|c|c|}
\hline Calm, equable (with people) ${ }^{a}$ & .42 & .76 \\
\hline Enthusiastic, spirited ${ }^{\mathrm{a}}$ & .42 & .77 \\
\hline Creative, inventive ${ }^{a}$ & .41 & .76 \\
\hline Sociable (with people) ${ }^{a}$ & .41 & .76 \\
\hline Curious, inquisitive $^{a}$ & .40 & .75 \\
\hline Friendly (to dolphins) ${ }^{a}$ & .40 & .75 \\
\hline Shy, timid ${ }^{\text {a }}$ & .40 & .76 \\
\hline Flexible, adaptable ${ }^{a}$ & .39 & .74 \\
\hline Impulsive $^{\text {a }}$ & .39 & .74 \\
\hline Easygoing $^{\mathrm{a}}$ & .38 & .74 \\
\hline Helpful (to people) ${ }^{\mathrm{a}}$ & .37 & .73 \\
\hline Predictable, consistent ${ }^{a}$ & .37 & .73 \\
\hline Punctual, prompt ${ }^{\mathrm{a}}$ & .37 & .73 \\
\hline Affectionate, warm (with people) ${ }^{a}$ & .35 & .71 \\
\hline Calm, equable (with dolphins) ${ }^{a}$ & .35 & .71 \\
\hline Independent $^{\mathrm{a}}$ & .34 & .70 \\
\hline Helpful (to dolphins) ${ }^{a}$ & .33 & .69 \\
\hline Scatterbrained $^{\text {a }}$ & .33 & .69 \\
\hline Aggressive $^{\mathrm{a}}$ & .32 & .68 \\
\hline Cautious $^{\text {a }}$ & .32 & .68 \\
\hline Irritable $^{a}$ & .32 & .68 \\
\hline Excitable $^{\text {a }}$ & .29 & .65 \\
\hline Affectionate, warm (with dolphins) ${ }^{a}$ & .28 & .64 \\
\hline Sociable (with dolphins) ${ }^{a}$ & .28 & .64 \\
\hline Vocal $^{\text {a }}$ & .25 & .60 \\
\hline Persistent $^{\text {a }}$ & .21 & .54 \\
\hline Decisive $^{b}$ & .19 & .44 \\
\hline Thoughtful (of dolphins) ${ }^{b}$ & .18 & .42 \\
\hline Thoughtful (of people) ${ }^{b}$ & .13 & .32 \\
\hline Perceptive (of people) ${ }^{b}$ & .08 & .22 \\
\hline Perceptive (of dolphins) ${ }^{b}$ & .06 & .17 \\
\hline$M$ & .37 & .70 \\
\hline$S D$ & .12 & .15 \\
\hline
\end{tabular}

Note. ${ }^{\text {a }}$ One of the 42 items that all dolphins were rated on; interrater reliabilities of these items were based on 522 observations by 78 raters of 115 subjects $(k=4.54)$. ${ }^{b}$ Interrater reliabilities of the seven items were based on the subset of dolphins rated on these items; interrater reliabilities of these items were based on 300 observations by 51 raters of 92 subjects $(k=3.26)$.

\section{Initial Exploratory Factor Analysis}

The scree plot (see Figure S1) indicated that there were five, six, or seven factors.

286 Parallel analysis indicated that six components had eigenvalues greater than those obtained

287 from random data (see Figure S2). The lowest BIC (-2548.053) was associated with a four- 
factor solution. The next lowest (-2545.132) was associated with a five-factor solution. Given these results, we extracted four, five, and six factors, which we rotated using the promax procedure. The fifth factor in the five-factor solution only loaded on the items "Affectionate, warm (with dolphins)" and "Affectionate, warm (with people)". The sixth factor in the sixfactor solution only had unique loadings on the items "Thoughtful (of dolphins)" and "Thoughtful (of people)"; the fifth factor in this solution only had unique loadings on “Affectionate, warm (with dolphins)" and "Affectionate, warm (with people)". Based on these results, we judged that the five- and six-factor solutions should not be retained. only loaded on the two variants of a single trait, and all four of its factors were interpretable. The factor correlations from this solution ranged from very small to medium in size, and the promax-rotated factors did not differ from their varimax-rotated counterparts (congruence coefficients were equal to $.99, .96, .98$, and .97$)$. We therefore interpreted the varimax-rotated factors. However, the resulting varimax- and promax-rotated solutions (see Table S1) were problematic in that none of the factors had salient loadings on eight $(\sim 16 \%)$ and nine $(\sim 18 \%)$ items, respectively. Moreover, the items that referred to "people" and to "dolphins" measured the same constructs, that is, in nearly all cases, the same factor loaded on both versions of the item. This finding suggests that, by including both versions of the items, we did the equivalent of including the same item twice. Because this might distort the factor structure, we conducted preregistered analyses that only included one version of each of these items.

\section{Preregistered Exploratory Factor Analyses of Dolphin-Directed Traits}

The scree plot indicated that there were four or five factors (see Figure S3). Parallel analysis indicated that five components had eigenvalues greater than those derived from random data (see Figure S4). The lowest BIC (-1895.001) was associated with a four-factor solution and the next lowest was associated with a five-factor solution (-1875.723). Given 
313 these results, we retained four factors (see Tables 2 and S2) which explained $49 \%$ of the

314 variance. Two factor correlations were medium in size with one being close to large. The

315 factor congruences were $.98, .98, .94$, and .97 , with the lowest of these indicating that one of

316 the oblique factors may differ from its orthogonal counterpart. We thus interpreted the

317 promax-rotated factors. The first factor (Directedness) was characterized by loadings that

318 described behavioral consistency and focus, boldness, and low emotional arousal. The second

319 factor (Openness) was characterized by loadings that described a tendency to be active and to

320 investigate the environment. The third factor (Sociability) was characterized by loadings on

321 traits related to extraversion and to agreeableness. The fourth factor (Disagreeableness) was

322 characterized by loadings on items describing a tendency to be aggressive, jealous, despotic,

323 and obstinate.

324 Table 2

325 Standardized Loadings (Pattern Matrix) and Factor Correlations for Analysis in Which

326 People-Directed Items were Excluded

327

\begin{tabular}{lrrrrr}
\hline \multirow{1}{*}{ Item } & \multicolumn{5}{c}{ Factor } \\
\cline { 2 - 5 } & Dir ${ }^{\mathrm{R}}$ & Opn & \multicolumn{1}{c}{ Soc } & \multicolumn{1}{c}{ Dis } & \multicolumn{1}{c}{$h^{2}$} \\
\hline Scatterbrained & $\mathbf{- . 9 6}$ & -.10 & .33 & .14 & .746 \\
Shy, timid & $\mathbf{- . 9 0}$ & -.08 & .15 & -.11 & .737 \\
Distractible & $\mathbf{- . 8 3}$ & -.04 & .10 & .18 & .652 \\
Clumsy & $\mathbf{- . 7 0}$ & -.10 & .17 & .02 & .416 \\
Submissive & $\mathbf{- . 6 9}$ & .17 & .25 & -.42 & .527 \\
Fearful, nervous & $\mathbf{- . 6 7}$ & .00 & -.17 & -.10 & .583 \\
Bold, brave & $\mathbf{. 5 8}$ & .27 & .18 & .33 & .699 \\
Erratic & $\mathbf{- . 5 4}$ & .15 & -.16 & .28 & .551 \\
Decisive & $\mathbf{. 5 3}$ & .16 & .11 & .19 & .433 \\
Punctual, prompt & $\mathbf{. 4 3}$ & .28 & .27 & -.12 & .478 \\
Cautious & -.32 & -.30 & -.04 & -.15 & .269 \\
Perceptive & .24 & -.02 & .08 & -.07 & .092 \\
Thoughtful & .16 & -.15 & .12 & -.13 & .117 \\
Playful & -.07 & $\mathbf{. 9 1}$ & .17 & -.24 & .767 \\
Active, energetic & .03 & $\mathbf{. 8 5}$ & -.11 & -.15 & .649 \\
Enthusiastic, spirited & .12 & $\mathbf{. 8 2}$ & .23 & -.05 & .778 \\
Creative, inventive & .06 & $\mathbf{. 8 0}$ & .14 & -.04 & .675 \\
Curious, inquisitive & -.04 & $\mathbf{. 7 4}$ & .25 & .06 & .644 \\
\hline
\end{tabular}




\begin{tabular}{|c|c|c|c|c|c|}
\hline Lazy & -.35 & -.74 & .37 & .32 & .566 \\
\hline Exhibitionistic, flamboyant & -.13 & .60 & .13 & .19 & .488 \\
\hline Excitable & -.36 & .60 & -.23 & -.06 & .537 \\
\hline Intelligent & .38 & .60 & -.10 & .06 & .533 \\
\hline Vocal & -.01 & .49 & .00 & .01 & .240 \\
\hline Impulsive & -.35 & .41 & -.10 & .29 & .504 \\
\hline Persistent & .26 & .40 & .21 & .17 & .408 \\
\hline Friendly & -.34 & .19 & .84 & -.16 & .647 \\
\hline Helpful & -.13 & .09 & .76 & -.05 & .517 \\
\hline Sociable & -.09 & .27 & .59 & .11 & .393 \\
\hline Predictable, consistent & .18 & -.11 & .49 & .02 & .356 \\
\hline Easygoing & .36 & -.17 & .45 & .01 & .498 \\
\hline Suspicious & -.40 & -.06 & -.45 & -.03 & .543 \\
\hline Flexible, adaptable & .27 & .41 & .44 & -.08 & .585 \\
\hline Calm, equable & .31 & -.16 & .43 & -.03 & .438 \\
\hline Affectionate, warm & -.06 & .02 & .38 & .11 & .117 \\
\hline Cunning & .12 & .00 & -.30 & .21 & .147 \\
\hline Stubborn & -.27 & -.46 & .22 & .81 & .598 \\
\hline Jealous & -.05 & .18 & .11 & .69 & .581 \\
\hline Dominant & .52 & -.14 & -.07 & .65 & .592 \\
\hline Aggressive & -.03 & .18 & .07 & .56 & .414 \\
\hline Independent & .23 & -.09 & -.05 & .56 & .324 \\
\hline Irritable & -.10 & -.03 & -.15 & .49 & .322 \\
\hline Temperamental & -.26 & .22 & -.33 & .36 & .548 \\
\hline \multirow[t]{3}{*}{ Proportion of variance } & .16 & .16 & .09 & .08 & \\
\hline & \multicolumn{4}{|c|}{ Factor Correlations } & \\
\hline & Dir & Opn & Soc & Dis & \\
\hline Dir & 1.00 & & & & \\
\hline Opn & .08 & 1.00 & & & \\
\hline Soc & .49 & .04 & 1.00 & & \\
\hline Dis & -.05 & .38 & -.25 & 1.00 & \\
\hline
\end{tabular}

Note. $N=134$. Factors were rotated using the promax procedure. Dir $=$ Directedness, Opn $=$ Openness, Soc $=$ Sociability, Dis $=$ Disagreeableness. Salient loadings are in bold. $h^{2}=$ communalities. ${ }^{\mathrm{R}}$ Factor loadings multiplied by -1 .

Although we decided to retain four factors, we also extracted five factors, which we subjected to a promax rotation. The first four factors resembled those from the four-factor solution shown in Table 2. The fifth factor loaded on the items "Cautious" and "Perceptive".

336 One interpretation of this factor is that it was a facet of neuroticism. 
The scree plot indicated that there were four or five factors (see Figure S5). Parallel

339

340

341

342

343

344

345

346

347

348

349

350

351

352

353

354

355

analysis indicated that four components had eigenvalues greater than those derived from random data (see Figure S6). The lowest BIC (-1984.411) was associated with a four-factor solution. The next lowest BIC (-1967.476) was associated with a five-factor solution. Given these results, we extracted four factors (see Tables 3 and S3) which explained $51 \%$ of the variance. Except for one medium-sized correlation, the factor correlations were small. There were no major differences between the varimax and promax-rotated solutions: one congruence coefficient was equal to .96 , two were equal to .98 , and one was equal to .99 . We thus interpreted the varimax-rotated structure. Aside from the fact that the item "Dominant" had its largest loading (.58) on directedness rather than disagreeableness (.50), these factors were nearly identical to those from the previous preregistered analysis.

To test whether the two structures were rotational variants, we used a custom $\mathrm{R}$ function to conduct a targeted orthogonal Procrustes rotation (McCrae et al., 1996). For this analysis, the loading matrix was the varimax-rotated structure that included the humandirected items and the target matrix was the varimax-rotated structure that included the dolphin-directed items. The factor congruences were $.964, .978, .932$, and .946 for directedness, openness, sociability, and disagreeableness, respectively, the congruence for the overall structure was .959 , and only five items had congruences below .95 (see Table S4).

\section{Table 3}

Standardized Loadings (Pattern Matrix) and Factor Correlations for Analysis in Which Dolphin-Directed Items were Excluded

\begin{tabular}{lrrrrr}
\hline \multirow{1}{*}{ Item } & \multicolumn{5}{c}{ Factor } \\
\cline { 2 - 5 } & Opn & Dir $^{\mathrm{R}}$ & Soc & Dis & $h^{2}$ \\
\hline Playful & $\mathbf{. 8 7}$ & -.01 & .11 & -.13 & .779 \\
Enthusiastic, spirited & $\mathbf{. 8 2}$ & .19 & .22 & .02 & .766 \\
Creative, inventive & $\mathbf{. 8 1}$ & .15 & .08 & .02 & .679 \\
Curious, inquisitive & $\mathbf{. 7 9}$ & .07 & .12 & .09 & .647 \\
Active, energetic & $\mathbf{. 7 8}$ & .06 & -.12 & -.03 & .624 \\
Exhibitionistic, flamboyant & $\mathbf{. 6 5}$ & -.04 & .03 & .27 & .496
\end{tabular}




\begin{tabular}{lrrrrr} 
Intelligent & $\mathbf{. 6 1}$ & $\mathbf{. 4 2}$ & -.07 & .07 & .558 \\
Lazy & $\mathbf{- . 6 1}$ & -.27 & .19 & .21 & .523 \\
Excitable & $\mathbf{. 5 2}$ & -.33 & -.34 & .12 & .511 \\
Vocal & $\mathbf{. 4 8}$ & .03 & -.06 & .07 & .237 \\
Persistent & $\mathbf{. 4 8}$ & .33 & .26 & .14 & .422 \\
Impulsive & $\mathbf{. 4 5}$ & -.24 & -.34 & .37 & .507 \\
Cautious & -.36 & -.33 & -.13 & -.09 & .264 \\
Scatterbrained & -.07 & $\mathbf{- . 8 1}$ & -.09 & .21 & .721 \\
Shy, timid & -.15 & $\mathbf{- . 8 1}$ & -.18 & .01 & .712 \\
Distractible & .00 & $\mathbf{- . 6 8}$ & -.19 & .31 & .602 \\
Submissive & .06 & $\mathbf{- . 6 7}$ & .06 & -.30 & .545 \\
Bold, brave & $\mathbf{. 4 0}$ & $\mathbf{. 6 6}$ & .22 & .19 & .674 \\
Fearful, nervous & -.08 & $\mathbf{- . 6 5}$ & -.36 & .05 & .571 \\
Clumsy & -.11 & $\mathbf{- . 6 2}$ & -.12 & .11 & .426 \\
Dominant & .05 & $\mathbf{. 5 8}$ & -.02 & $\mathbf{. 5 0}$ & .596 \\
Decisive & .22 & $\mathbf{. 5 4}$ & .29 & .13 & .446 \\
Punctual, prompt & .30 & $\mathbf{. 4 2}$ & $\mathbf{. 4 1}$ & -.18 & .472 \\
Friendly & .22 & -.14 & $\mathbf{. 7 9}$ & .06 & .699 \\
Helpful & .15 & -.02 & $\mathbf{. 7 9}$ & .03 & .648 \\
Calm, equable & -.07 & .22 & $\mathbf{. 7 9}$ & .02 & .677 \\
Easygoing & -.09 & .35 & $\mathbf{. 6 3}$ & -.10 & .539 \\
Suspicious & -.14 & $\mathbf{- . 4 2}$ & $\mathbf{- . 6 0}$ & .10 & .569 \\
Predictable, consistent & -.04 & .21 & $\mathbf{. 5 7}$ & -.07 & .372 \\
Temperamental & .25 & -.18 & $\mathbf{- . 5 6}$ & $\mathbf{. 4 3}$ & .587 \\
Sociable & .06 & .14 & .13 & .08 & \\
Flexible, adaptable & $\mathbf{. 5 2}$ & -.07 & $\mathbf{. 5 5}$ & .11 & .595 \\
Erratic & $\mathbf{. 4 6}$ & .31 & $\mathbf{. 5 1}$ & -.14 & .588 \\
Thoughtful & .18 & $\mathbf{- . 4 2}$ & $\mathbf{- . 4 8}$ & .35 & .563 \\
Cunning & -.09 & .14 & .36 & -.02 & .159 \\
Perceptive & .04 & .12 & -.32 & .21 & .162 \\
Stubborn & .08 & .10 & .22 & -.10 & .074 \\
Jealous & -.23 & -.13 & -.02 & $\mathbf{. 7 2}$ & .593 \\
Aggressive & .37 & .07 & .00 & $\mathbf{. 6 7}$ & .597 \\
Irritable & .31 & .06 & .03 & $\mathbf{. 6 0}$ & .462 \\
Independent & .06 & -.05 & -.22 & $\mathbf{. 5 3}$ & .338 \\
Affectionate, warm & .04 & .29 & -.06 & $\mathbf{. 5 1}$ & .347 \\
Proportion of variance & .11 & .04 & -.28 & .098 \\
\hline & & & & \\
& .06 & &
\end{tabular}


The interrater reliabilities and internal consistency alphas are presented in Table 4.

367 The reliabilities of unit-weighted factor scores that were based on the results of our

368 preregistered analyses ranged from acceptable to excellent.

\section{Table 4}

Interrater and Internal Consistent Reliability Estimates for Unit-Weighted Factor Scores Based on Salient Loadings from Varimax-Rotated Factors

\begin{tabular}{lrrr}
\hline \multicolumn{1}{c}{ Factor } & $I C C(3,1)$ & $I C C(3, k)$ & \multicolumn{2}{c}{ Standardized alpha } \\
\cline { 2 - 4 } Dolphin-oriented & & & \\
Openness & .60 & .87 & .90 \\
Directedness $^{\text {a }}$ & .59 & .87 & .86 \\
Sociability & .57 & .86 & .84 \\
Disagreeableness & .64 & .89 & .77 \\
& & & \\
Human-oriented & & & .90 \\
Openness & .60 & .87 & .87 \\
Directedness a & .63 & .88 & .68 \\
Sociability & .65 & .89 & .76 \\
Disagreeableness & .60 & .87 & \\
\hline
\end{tabular}

373

Note. Interrater reliability estimates were based on 522 observations of 115 subjects by 78 raters $(k=4.54) .{ }^{a}$ Directedness scores were only based on the items with salient items that all dolphins were rated on. We therefore did not include the items decisive, clumsy, and distractible in these scores.

\section{Discussion}

We found interrater reliabilities of single ratings for items that were comparable to those found in previous studies of marine mammal personality (Ciardelli et al., 2017; Úbeda et al., 2019). These reliability estimates were also comparable to the repeatabilities of behavioral tests, such as the novel object test, and were, in fact, higher than the repeatabilities found in studies of many vertebrates (Bell et al., 2009). We also found that, in the context of this sample and the types of humans that the dolphins would have interacted with, that, when there were two versions of an item, one referring to "people" and one referring to "dolphins", both versions loaded on the same factor. In other words, dolphins rated as, for example, "Friendly to dolphins", tended to also be rated as "Friendly to people". In two preregistered exploratory factor analyses, one that excluded items directed to people and another that 
389

390

391

392

393

394

395

396

397

398

399

400

401

402

403

404

405

406

407

408

409

410

411

412

excluded items directed to dolphins, we found evidence for four similar domains, namely openness, directedness, sociability, and disagreeableness. The interrater reliabilities and internal consistency reliabilities of these domains were high.

There were similarities and differences between the personality structure that we found and the personality structures of orcas (Úbeda et al., 2019) and California sea lions (Ciardelli et al., 2017). In terms of similarities, as in the present study, neither the study of orcas nor that of California sea lions found evidence for a neuroticism domain. Similarly, orca extraversion and California sea lion extraversion/impulsivity loaded on many of the same traits that openness loaded on in dolphins. In terms of differences, orca dominance and California sea lion dominance/confidence loaded on many of the same traits that dolphin disagreeableness and directedness loaded on, indicating that the traits related to dominance in dolphins were more weakly intercorrelated than they were in orcas or California sea lions.

Orcas and California sea lions also differed from dolphins in terms of the location of items related to conscientiousness. In dolphins, these items loaded onto directedness, which was named after a personality style characterized by high conscientiousness and low neuroticism (Costa \& McCrae, 1998). In orcas, these items loaded onto "conscien-agreeableness", which resembled a style of character related to being an effective altruist (Costa \& McCrae, 1998) and careful, which resembled a style of anger control related to being easy-going (Costa \& McCrae, 1998). In California sea lions, these items loaded onto reactivity/undependability, which resembled orca "conscien-agreeableness". Finally, unlike dolphins, neither orcas nor California sea lions appeared to have a sociability domain characterized by traits related to extraversion and agreeableness. Collectively, because our study and the studies by Úbeda et al. (2019) and Ciardelli et al. (2017) used different, albeit partially overlapping, questionnaires, attempts to interpret the evolutionary bases of these differences need to be 
413

414

415

416

417

418

419

420

421

422

423

424

425

426

427

428

429

430

431

432

433

434

435

436

made with caution until large, multi-site studies of these species are conducted using the same personality questionnaire.

Our finding of a dolphin openness domain supports a pattern seen in primates

whereby such dimensions are found in intelligent, group-living species, such as chimpanzees (Dutton, 2008; Freeman et al., 2013; King \& Figueredo, 1997) and bonobos (Weiss et al., 2015). Consistent with this explanation is the absence of an openness domain in orangutans Pongo spp. (Weiss et al., 2006), which are intelligent species that do not live in stable social groups with continuous and daily physical interactions (Galdikas, 1985a, 1985b, 1985c).

Further support comes from a study of horses, which are relatively intelligent (Matsuzawa, 2017), live in stable social groups (McCort, 1984), and have an openness domain (Lloyd et al., 2008). Further studies on taxa varying in intelligence and sociality will help determine the extent to which one or both of these factors contributed to the evolution of openness.

We did not find strong evidence for a dominance domain. Instead, in our preregistered analyses, we found that two cardinal markers of dominance ("Dominant" and "Submissive") were located between directedness and disagreeableness. These findings are unusual since strong dominance domains surface repeatedly in studies of nonhuman primates (Freeman \& Gosling, 2010) and other species (Ciardelli et al., 2017; Gartner, 2014; Gartner \& Weiss, 2013; Gosling \& John, 1999; Jones \& Gosling, 2005; Úbeda et al., 2019). Moreover, with the exception of an early study of personality in dogs that identified a factor labeled "emotion VI" (Cattell \& Korth, 1973, pp. 22-23, 26-27), a directedness domain has not been identified in nonhuman primates (Freeman \& Gosling, 2010), felids (Gartner et al., 2014; Gartner \& Weiss, 2013), marine mammals (Ciardelli et al., 2017; Úbeda et al., 2019), or other species (Gosling, 2001; Gosling \& John, 1999). It has also not been found in more recent studies of dogs (Jones \& Gosling 2005). 
The closest match for this configuration of traits occurs in rhesus macaques. However, in that species, only the item "Dominant" was split between two domains, namely dominance (loading =.57) and confidence (loading = .55) (Weiss et al., 2011). Confidence in rhesus macaques was also more strongly defined by items relating to neuroticism than was directedness in dolphins, the latter being more strongly defined by loadings on items relating to low conscientiousness.

One possible explanation for these findings is that our questionnaire did not sample enough traits related to dominance. However, this explanation can probably be excluded given that, as noted, dominance domains show up in multiple species (Freeman \& Gosling, 2010; Gartner et al., 2014; Gartner \& Weiss, 2013; Gosling, 2001; Gosling \& John, 1999), including marine mammals (Ciardelli et al., 2017; Úbeda et al., 2019) despite the items in questionnaires varying between studies. Also, in studies of nonhuman primates, differences have been identified between the dominance domains of rhesus macaques (Weiss et al., 2011) and, for example, chimpanzees (Weiss et al., 2009), both of which were rated on the same questionnaire. Thus, an alternative explanation is that our findings reflect something about the nature of dominance-related traits in dolphins. For example, unlike rhesus macaques (Thierry, 2000), bottlenose dolphins are not especially despotic (Yamamoto et al., 2015). In a similar vein, like humans, where traits like "Dominant" and "Submissive" are located between extraversion and agreeableness (McCrae \& Costa, 1989; Traupman et al., 2009), dolphin societies are not strongly characterized by a hierarchy. Although captive dolphins express dominance and form dominance hierarchies, these hierarchies are not always strongly maintained and males' priority access to females and to food are based on size rather than on the results of contests (Shane et al., 1986). Orcas, however, appear to have a dominance 460 personality domain (Úbeda et al., 2019) despite not showing signs of forming dominance 461 hierarchies (Ford et al., 2011). As such, the link between despotism, dominance hierarchies, 
and the clustering of personality traits related to aggression and social competence remains unclear, and may be unique to terrestrial species, nonhuman primates, or macaques (Adams et al., 2015).

Like chimpanzees, bonobos, orangutans, and humans (see Aureli et al., 2008 for a review), dolphins' relationships are structured around fission-fusion groupings (Lusseau et al., 2006; Moreno \& Acevedo-Gutiérrez, 2016; Tsai \& Mann, 2013) and male dolphins (Connor et al., 1999, 2001; Connor et al., 1992), like male chimpanzees (Gilby et al., 2013), form temporary alliances. Nevertheless, unlike dolphins, chimpanzees (Dutton, 2008; Freeman et al., 2013; King \& Figueredo, 1997), bonobos (Weiss et al., 2015), orangutans (Weiss et al., 2006), and humans (Digman, 1990) have independent extraversion and agreeableness factors. Dolphin sociability, instead, is similar to factors found in, for example, brown capuchin monkeys (Morton et al., 2013) and mountain gorillas (Eckardt et al., 2015), which live in stable cohesive groups (Fragaszy et al., 2004; Robbins, 1995). Group structure (e.g. fission-fusion groupings) may therefore not be a sufficient explanation for the evolution of personality factors like sociability and thus other aspects of sociality may be worth examining. More studies are needed on populations and species that differ in group size and structure, as well as the content, quality, and frequency of their social interactions (Hinde, 1976).

Dolphins appear to lack a strong neuroticism domain. Items related to neuroticism are found alongside those related to conscientiousness and so help to comprise the directedness domain. Eckardt et al. (2015) found no evidence for a neuroticism domain in their study of mountain gorillas and proposed that neuroticism may not emerge in species that live in stable and predictable environments. However, dolphins like bonobos (Weiss et al., 2015) lack neuroticism and evolved in relatively unpredictable environments. For example, unlike mountain gorillas, dolphins and bonobos do not live in stable social groups (Aureli et al., 
487

488

489

490

491

492

493

494

495

496

497

498

499

500

501

502

503

504

505

506

507

508

509

510

511

2008; Lusseau et al., 2006; Moreno \& Acevedo-Gutiérrez, 2016; Tsai \& Mann, 2013) and

primarily eat foods that are spatially and temporally dispersed (Gannon \& Waples, 2004;

Serckx et al., 2015). Even in captivity, where such conditions are arguably 'more predictable' than in the wild, social factors still vary for these animals (e.g., births, deaths, or changes in dominance) and diet can change seasonally depending on the availability of items from local markets (F. Blake Morton, personal observation). As such, Eckardt et al.'s proposed explanation is wanting. To further test Eckardt et al.'s hypothesis, research on wild and captive animals must define "environmental unpredictability", particularly whether those effects are qualitative (e.g., type of unpredictability, such as social versus ecological) or quantitative (e.g., degree of unpredictability). It will also be important to test whether the degree of neuroticism varies across species as a function of the level of environmental unpredictability that existed throughout the evolution of that species, rather than conditions presently experienced by extant species.

Previous findings, such as those from studies of common marmosets (Iwanicki \& Lehmann, 2015; Koski et al., 2017), suggest that conscientiousness evolved in species that regularly engage in behaviors that require social attentiveness. Dolphins, however, do not possess a conscientiousness domain despite engaging in socially attentive behaviors (e.g., learning by observation how to use tools; Krützen et al., 2005). Social attentiveness in general, or attentiveness related to social learning and tool use specifically, may therefore not be a necessary and sufficient condition for conscientiousness to evolve. One condition that may be necessary for conscientiousness to evolve is for species to have physical appendages that require attentional control to facilitate physical interactions with the environment, including actions related to object manipulation and providing infant care (Byrne et al., 2009). A finding consistent with this explanation is that something like conscientiousness has been found in Asian elephants Elephas maximus (Seltmann et al., 2018), which use their 
512

trunks to manipulate tools and other objects. A second finding comes from a study of

chimpanzees, which found that conscientiousness is associated with requiring fewer tries to

514

515

516

517 touch an intended target (Altschul et al., 2017). To test this 'morphology' hypothesis further, researchers might compare the personality structure of meerkats Suricata suricatta, which are cooperative breeders that provide parental care using their hands (Russell et al., 2003), to the personality structure of corvids Corvus moneduloides, which learn to make tools by watching others but lack hands to facilitate their learning (Taylor et al., 2012). If morphology—in addition to social attentiveness - is necessary for conscientiousness to evolve, we would expect to find such a domain in meerkats, but not in corvids.

Our findings relating to the absence of neuroticism and dominance domains, and the presence of the directedness domain, should be considered tentative. When we extracted more factors than we were probably justified to, we found evidence that neuroticism and dominance domains might exist, but that the questionnaire did not include enough items related to these constructs. It is therefore important to add more items related to neuroticism and dominance to this questionnaire, and then use it to study personality in bottlenose dolphins and other cetaceans. Further work is also needed using a combination of ratings, behavioral observations, and cognitive task data - all of which can provide complementary insights into personality structure (Koski, 2011; Weiss \& Adams, 2013).

Our study suggests that dolphin personality resembles that of primates and other terrestrial species, including humans, with the exception that dolphins possess a directedness domain and do not possess a neuroticism domain. The overlap in personality structure between dolphins and other species suggests that selective pressures, such as those related to group structure, terrestrial lifestyles, morphology, and social learning or tool use, are not necessary for particular domains to evolve. Further work on cetaceans, other aquatic 
536 mammals, and other vertebrates will lead to a better understanding of the evolutionary forces

537 that unite and divide species that inhabit the surface and depths of our planet. 


\section{References}

539

540

Adams, M. J., Majolo, B., Ostner, J., Schuelke, O., De Marco, A., Thierry, B., Engelhardt,

541

542

543

544

545

546

547

548

549

550

551

552

553

554

555

556

557

558

559

560

561 A., Widdig, A., Gerald, M. S., \& Weiss, A. (2015). Personality structure and social style in macaques. Journal of Personality and Social Psychology, 109(2), 338-353. https://doi.org/10.1037/pspp0000041

Altschul, D. M., Wallace, E. K., Sonnweber, R., Tomonaga, M., \& Weiss, A. (2017). Chimpanzee intellect: personality, performance and motivation with touchscreen tasks. Royal Society Open Science, 4(5), Article 170169. https://doi.org/10.1098/rsos.170169

Alvergne, A., Jokela, M., \& Lummaa, V. (2010). Personality and reproductive success in a high-fertility human population. Proceedings of the National Academy of Sciences of the United States of America, 107(26), 11745-11750.

https://doi.org/10.1073/pnas.1001752107

Au, W. W. L. (1993). The sonar of dolphins. Springer-Verlag.

Auerswald, M., \& Moshagen, M. (2019). How to determine the number of factors to retain in exploratory factor analysis: a comparison of extraction methods under realistic conditions. Psychological Methods, 24(4), 468-491. https://doi.org/10.1037/met0000200

Aureli, F., Schaffner, C. M., Boesch, C., Bearder, S. K., Call, J., Chapman, C. A., Connor, R., Di Fiore, A., Dunbar, R. I. M., Henzi, S. P., Holekamp, K., Korstjens, A. H., Layton, R., Lee, P., Lehmann, J., Manson, J. H., Ramos-Fernandez, G., Strier, K. B., \& van Schaick, C. P. (2008). Fission-fusion dynamics new research frameworks. Current Anthropology, 49(4), 627-654. https://doi.org/10.1086/586708 
Bell, A. M., Hankison, S. J., \& Laskowski, K. L. (2009). The repeatability of behaviour: a meta-analysis. Animal Behaviour, 77(4), 771-783. https://doi.org/10.1016/j.anbehav.2008.12.022

Bernstein, I. S. (1981). Dominance - the baby and the bathwater. Behavioral and Brain Sciences, 4(3), 419-429. https://doi.org/10.1017/S0140525X00009614

Boehm, C. (1999). Hierarchy in the forest: The evolution of egalitarian behavior. Harvard University Press.

Brent, L. J. N., Semple, S., MacLarnon, A., Ruiz-Lambides, A., Gonzalez-Martinez, J., \& Platt, M. J. (2014). Personality traits in rhesus macaques (Macaca mulatta) are heritable but do not predict reproductive output. International Journal of Primatology, 35(1), 188-209. https://doi.org/10.1007/s10764-013-9724-6

Bruck, J. N. (2013). Decades-long social memory in bottlenose dolphins. Proceedings of the Royal Society B: Biological Sciences, 280(1768), Article 20131726. https://doi.org/10.1098/rspb.2013.1726

Burkart, J. M., Allon, O., Amici, F., Fichtel, C., Finkenwirth, C., Heschl, A., Huber, J., Isler, K., Kosonen, Z. K., Martins, E., Meulman, E. J., Richiger, R., Rueth, K., Spillmann, B., Wiesendanger, S., \& van Schaik, C. P. (2014). The evolutionary origin of human hyper-cooperation. Nature Communications, 5, Article 4747. https://doi.org/10.1038/ncomms5747

Byrne, R. W., Bates, L. A., \& Moss, C. J. (2009). Elephant cognition in primate perspective. Comparative Cognition \& Behavior Reviews, 4, 65-79. https://doi.org/10.3819/ccbr.2009.40009

Byrne, R. W., \& Whiten, A. (1988). Machiavellian intelligence: social expertise and the evolution of intellect in monkeys, apes, and humans. Clarendon Press/Oxford University Press. 
587

588

589

590

591

592

593

594

595

596

597

598

599

600

601

602

603

604

605

606

607

608

609

610

Cameron, E. Z., Setsaas, T. H., \& Linklater, W. L. (2009). Social bonds between unrelated females increase reproductive success in feral horses. Proceedings of the National Academy of Sciences of the United States of America, 106(33), 13850-13853. https://doi.org/10.1073/pnas.0900639106

Capitanio, J. P. (1999). Personality dimensions in adult male rhesus macaques: Prediction of behaviors across time and situation. American Journal of Primatology, 47(4), 299320. https://doi.org/10.1002/(SICI)1098-2345(1999)47:4<299::AID-AJP3>3.0.CO;2$\underline{\mathrm{P}}$

Cattell, R. B., \& Korth, B. (1973). The isolation of temperament dimensions in dogs. Behavioral Biology, 9(1), 15-30. https://doi.org/10.1016/S0091-6773(73)80165-8

Ciardelli, L. E., Weiss, A., Powell, D. M., \& Reiss, D. (2017). Personality dimensions of the captive California sea lion (Zalophus californianus). Journal of Comparative Psychology, 131(1), 50-58. https://doi.org/10.1037/com0000054

Clutton-Brock, T. H., \& Huchard, E. (2013). Social competition and selection in males and females. Philosophical Transactions of the Royal Society B Biological Sciences, 368(1631), Article 20130074. https://doi.org/10.1098/rstb.2013.0074

Coelho, C. G., Falótico, T., Izar, P., Mannu, M., Resende, B. D., Siqueira, J. O., \& Ottoni, E. B. (2015). Social learning strategies for nut-cracking by tufted capuchin monkeys (Sapajus spp.). Animal Cognition, 18(4), 911-919. https://doi.org/10.1007/s10071$\underline{015-0861-5}$

Connor, R. C., Heithaus, M. R., \& Barre, L. M. (1999). Superalliance of bottlenose dolphins. Nature, 397(6720), 571-572. https://doi.org/10.1038/17501

Connor, R. C., Heithaus, M. R., \& Barre, L. M. (2001). Complex social structure, alliance stability and mating access in a bottlenose dolphin super-alliance. Proceedings of the 
611

612

613

614

615

616

617

618

619

620

621

622

623

624

625

626

627

628

629

630

631

632

633

Royal Society of London. Series B: Biological Sciences, 268(1464), 263-267. https://doi.org/10.1098/rspb.2000.1357

Connor, R. C., Smolker, R. A., \& Richards, A. F. (1992). Two levels of alliance formation among male bottlenose dolphins (Tursiops sp.). Proceedings of the National Academy of Sciences of the United States of America, 89(3), 987-990. https://doi.org/10.1073/pnas.89.3.987

Costa, P. T., Jr., \& McCrae, R. R. (1992). Revised NEO Personality Inventory (NEO-PI-R) and NEO Five-Factor Inventory (NEO-FFI) professional manual. Psychological Assessment Resources.

Costa, P. T., Jr., \& McCrae, R. R. (1995). Domains and facets: Hierarchical personality assessment using the Revised NEO Personality Inventory. Journal of Personality Assessment, 64(1), 21-50. https://doi.org/10.1207/s15327752jpa6401_2

Costa, P. T., Jr., \& McCrae, R. R. (1998). Manual supplement for the NEO-4. Psychological Assessment Resources.

Costa, P. T., Jr., Zonderman, A. B., McCrae, R. R., \& Williams, R. B., Jr. (1985). Content and comprehensiveness in the MMPI: An item factor analysis in a normal adult sample. Journal of Personality and Social Psychology, 48(4), 925-933. https://doi.org/10.1037/0022-3514.48.4.925

Cowlishaw, G., \& Dunbar, R. I. M. (1991). Dominance rank and mating success in male primates. Animal Behaviour, 41(6), 1045-1056. https://doi.org/10.1016/S0003$\underline{3472(05) 80642-6}$

Cronbach, L. J., \& Meehl, P. E. (1955). Construct validity in psychological tests. Psychological Bulletin, 52(4), 281-302. https://doi.org/10.1037/h0040957 
634

635

636

637

638

639

640

641

642

643

644

645

646

647

648

649

650

651

652

653

654

655

656

657

658

de Ruiter, J. R., \& van Hooff, J. A. R. A. M. (1993). Male dominance rank and reproductive success in primate groups. Primates, 34(4), 513-523. https://doi.org/10.1007/BF02382662

de Winter, J. C. F., Dodou, D., \& Wieringa, P. A. (2009). Exploratory factor analysis with small sample sizes. Multivariate Behavioral Research, 44(2), 147-181. https://doi.org/10.1080/00273170902794206

Deák, G. O. (2014). Development of adaptive tool-use in early childhood: Sensorimotor, social, and conceptual factors. In J. B. Benson (Ed.), Advances in Child Development and Behavior (Vol. 46, pp. 149-181). Elsevier. https://doi.org/10.1016/B978-0-12$\underline{800285-8.00006-6}$

Díaz López, B. (2020). When personality matters: personality and social structure in wild bottlenose dolphins, Tursiops truncatus. Animal Behaviour, 163, 73-84. https://doi.org/10.1016/j.anbehav.2020.03.001

Digman, J. M. (1990). Personality structure: Emergence of the Five-Factor Model. Annual Review of Psychology, 41, 417-440. https://doi.org/10.1146/annurev.ps.41.020190.002221

Dutton, D. M. (2008). Subjective assessment of chimpanzee (Pan troglodytes) personality: Reliability and stability of trait ratings. Primates, 49(4), 253-259. https://doi.org/10.1007/s10329-008-0094-1

Eckardt, W., Steklis, H. D., Steklis, N. G., Fletcher, A. W., Stoinski, T. S., \& Weiss, A. (2015). Personality dimensions and their behavioral correlates in wild Virunga mountain gorillas (Gorilla beringei beringei). Journal of Comparative Psychology, 129(1), 26-41. https://doi.org/10.1037/a0038370

Fedigan, L. M. (1983). Dominance and reproductive success in primates. American Journal of Physical Anthropology, 26(S1), 91-129. https://doi.org/10.1002/ajpa.1330260506 
659

660

661

662

663

664

665

666

667

668

669

670

671

672

673

674

675

676

677

678

679

680

681

682

Figueredo, A. J., Cox, R. L., \& Rhine, R. J. (1995). A generalizability analysis of subjective personality assessments in the stumptail macaque and the zebra finch. Multivariate Behavioral Research, 30(2), 167-197. https://doi.org/10.1207/s15327906mbr3002_3

Ford, M. J., Hanson, M. B., Hempelmann, J. A., Ayres, K. L., Emmons, C. K., Schorr, G. S., Baird, R. W., Balcomb, K. C., Wasser, S. K., Parsons, K. M., \& Balcomb-Bartok, K. (2011). Inferred paternity and male reproductive success in a killer whale (Orcinus orca) population. Journal of Heredity, 102(5), 537-553. https://doi.org/10.1093/jhered/esr067

Fragaszy, D. M., Eshchar, Y., Visalberghi, E., Resende, B., Laity, K., \& Izar, P. (2017). Synchronized practice helps bearded capuchin monkeys learn to extend attention while learning a tradition. Proceedings of the National Academy of Sciences, 114(30), 7798-7805. https://doi.org/10.1073/pnas.1621071114

Fragaszy, D. M., Visalberghi, E., \& Fedigan, L. M. (2004). The complete capuchin: The biology of the genus Cebus. Cambridge University Press.

Freeman, H. D., Brosnan, S. F., Hopper, L. M., Lambeth, S. P., Schapiro, S. J., \& Gosling, S. D. (2013). Developing a comprehensive and comparative questionnaire for measuring personality in chimpanzees using a simultaneous top-down/bottom-up design. American Journal of Primatology, 75(10), 1042-1053. https://doi.org/10.1002/ajp.22168

Freeman, H. D., \& Gosling, S. D. (2010). Personality in nonhuman primates: A review and evaluation of past research. American Journal of Primatology, 72(8), 653-671. https://doi.org/10.1002/ajp.20833

Furuichi, T., Connor, R., \& Hashimoto, C. (2013). Non-conceptive sexual interactions in monkeys, apes, and dolphins. In J. Yamagiwa \& L. Karczmarski (Eds.), Primates and 
683

684

685

686

687

688

689

690

691

692

693

694

695

696

697

698

699

700

701

702

703

704

705

706

cetaceans: Field research and conservation of complex mammalian societies (pp. 385-408). Springer Japan. https://doi.org/10.1007/978-4-431-54523-1_20

Galdikas, B. M. F. (1985a). Adult male sociality and reproductive tactics among orangutans at Tanjung Puting. Folia Primatologica, 45(1), 9-24. https://doi.org/10.1159/000156188

Galdikas, B. M. F. (1985b). Orangutan sociality at Tanjung-Puting. American Journal of Primatology, 9(2), 101-119. https://doi.org/10.1002/ajp.1350090204

Galdikas, B. M. F. (1985c). Subadult male orangutan sociality and reproductive behavior at Tanjung-Puting. American Journal of Primatology, 8(2), 87-99. https://doi.org/10.1002/ajp.1350080202

Gannon, D. P., \& Waples, D. M. (2004). Diets of coastal bottlenose dolphins from the U.S. mid-Atlantic coast differ by habitat. Marine Mammal Science, 20(3), 527-545. https://doi.org/10.1111/j.1748-7692.2004.tb01177.x

Gartner, M. C. (2014). Pet personality: A review. 75, 102-113. https://doi.org/10.1016/j.paid.2014.10.042

Gartner, M. C., Powell, D. M., \& Weiss, A. (2014). Personality structure in the domestic cat (Felis silvestris catus), Scottish wildcat (Felis silvestris grampia), clouded leopard (Neofelis nebulosa), snow leopard (Panthera uncia), and African lion (Panthera leo): A comparative study. Journal of Comparative Psychology, 128(4), 414-426. https://doi.org/10.1037/a0037104

Gartner, M. C., \& Weiss, A. (2013). Personality in felids: A review. Applied Animal Behaviour Science, 144(1-2), 1-13. https://doi.org/10.1016/j.applanim.2012.11.010

Gilby, I. C., Brent, L. J. N., Wroblewski, E. E., Rudicell, R. S., Hahn, B. H., Goodall, J., \& Pusey, A. E. (2013). Fitness benefits of coalitionary aggression in male chimpanzees. 
707

708

709

710

711

712

713

714

715

716

717

718

719

720

721

722

723

724

725

726

727

728

729

730

Behavioral Ecology and Sociobiology, 67(3), 373-381. https://doi.org/10.1007/s00265-012-1457-6

Glazko, G. V., \& Nei, M. (2003). Estimation of divergence times for major lineages of primate species. Molecular Biology and Evolution, 20(3), 424-434. https://doi.org/10.1093/molbev/msg050

Gorsuch, R. L. (1983). Factor analysis (2nd ed.). Lawrence Erlbaum Associates.

Gosling, S. D. (1998, Jun). Personality dimensions in spotted hyenas (Crocuta crocuta). Journal of Comparative Psychology, 112(2), 107-118. https://doi.org/10.1037/0735$\underline{7036.112 .2 .107}$

Gosling, S. D. (2001). From mice to men: What can we learn about personality from animal research? Psychological Bulletin, 127(1), 45-86. https://doi.org/10.1037/0033$\underline{2909.127 .1 .45}$

Gosling, S. D., \& Graybeal, A. (2007). Tree thinking: A new paradigm for integrating comparative data in psychology. The Journal of General Psychology, 134(2), 259277. https://doi.org/10.3200/GENP.134.2.259-278

Gosling, S. D., \& John, O. P. (1999). Personality dimensions in nonhuman animals: A crossspecies review. Current Directions in Psychological Science, 8(3), 69-75. https://doi.org/10.1111/1467-8721.00017

Gurven, M., von Rueden, C., Stieglitz, J., Kaplan, H., \& Eid Rodriguez, D. (2014). The evolutionary fitness of personality traits in a small-scale subsistence society. Evolution and Human Behavior, 35(1), 17-25. https://doi.org/10.1016/j.evolhumbehav.2013.09.002

Hall, K., \& Brosnan, S. F. (2017). Cooperation and deception in primates. Infant Behavior \& Development, 48, Part A, 38-44. https://doi.org/10.1016/j.infbeh.2016.11.007 
731 Hastie, G. D., Wilson, B., \& Thompson, P. M. (2003). Fine-scale habitat selection by coastal

732

733

734

735

736

737

738

739

740

741

742

743

744

745

746

747

748

749

750

751

752

753

754 bottlenose dolphins: application of a new land-based video-montage technique. Canadian Journal of Zoology, 81(3), 469-478. https://doi.org/10.1139/z03-028

Highfill, L. E., \& Kuczaj, S. A. (2007). Do bottlenose dolphins (Tursiops truncatus) have distinct and stable personalities? Aquatic Mammals, 33(3), 380-389. https://doi.org/10.1578/AM.33.3.2007.380

Hinde, R. A. (1976). Interactions, relationships and social structure. Man, 11(1), 1-17. https://doi.org/10.2307/2800384

Horn, J. L. (1965). A rationale and test for the number of factors in factor analysis. Psychometrika, 30, 179-185. https://doi.org/10.1007/BF02289447

Hrdy, S. B. (2009). Mothers and others. The evolutionary origins of mutual understanding. Belknap Press.

Inoue-Murayama, M., Yokoyama, C., Yamanashi, Y., \& Weiss, A. (2018). Common marmoset (Callithrix jacchus) personality, subjective well-being, hair cortisol level, and AVPRIa, OPRM1, and DAT genotypes. Scientific Reports, 8, Article 10255. https://doi.org/10.1038/s41598-018-28112-7

Isbell, L. A. (1991). Contest and scramble competition: patterns of female aggression and ranging behavior among primates. Behavioral Ecology, 2(2), 143-155. https://doi.org/10.1093/beheco/2.2.143

Iwanicki, S., \& Lehmann, J. (2015). Behavioral and trait rating assessments of personality in common marmosets (Callithrix jacchus). Journal of Comparative Psychology, 129(3), 205-217. https://doi.org/10.1037/a0039318

Jaakkola, K., Guarino, E., Donegan, K., \& King, S. L. (2018). Bottlenose dolphins can understand their partner's role in a cooperative task. Proceedings of the Royal Society 
755

756

757

758

759

760

761

762

763

764

765

766

767

768

769

770

771

772

773

774

775

776

777

B: Biological Sciences, 285(1887), Article 20180948. https://doi.org/10.1098/rspb.2018.0948

Jaakkola, K., Guarino, E., \& Rodriguez, M. (2010). Blindfolded imitation in a bottlenose dolphin (Tursiops truncatus). International Journal of Comparative Psychology, 23(4), 671-688.

Jokela, M., Alvergne, A., Pollet, T. V., \& Lummaa, V. (2011). Reproductive behavior and personality traits of the Five Factor Model. European Journal of Personality, 25(6), 487-500. https://doi.org/10.1002/per.822

Jones, A. C., \& Gosling, S. D. (2005). Temperament and personality in dogs (Canis familiaris): A review and evaluation of past research. Applied Animal Behaviour Science, 95(1-2), 1-53. https://doi.org/10.1016/j.applanim.2005.04.008

Kass, R. E., \& Raftery, A. E. (1995). Bayes Factors. Journal of the American Statistical Association, 90(430), 773-795. https://doi.org/10.2307/2291091

King, J. E., \& Figueredo, A. J. (1997). The Five-Factor Model plus Dominance in chimpanzee personality. Journal of Research in Personality, 31(2), 257-271. https://doi.org/10.1006/jrpe.1997.2179

Konečná, M., Weiss, A., Lhota, S., \& Wallner, B. (2012). Personality in Barbary macaques (Macaca sylvanus): Temporal stability and social rank. Journal of Research in Personality, 46(5), 581-590. https://doi.org/10.1016/j.jrp.2012.06.004

Koski, S. E. (2011). How to measure animal personality and why does It matter? Integrating the psychological and biological approaches to animal personality. In M. InoueMurayama, S. Kawamura, \& A. Weiss (Eds.), From genes to animal behavior: Social structures, personalities, communication by color (pp. 115-136). Springer. 
778 Koski, S. E., Buchanan-Smith, H., Ash, H., Burkart, J., Bugnyar, T., \& Weiss, A. (2017).

779

780

781

782

783

784

785

786

787

788

789

790

791

792

793

794

795

796

797

798

799

800

801

802 Common marmoset (Callithrix jacchus) personality. Journal of Comparative Psychology, 131(4), 326-336. https://doi.org/10.1037/com0000089

Krueger, K. (2008). Social ecology of horses. In J. Korb \& J. Heinze (Eds.), Ecology of Social Evolution (pp. 195-206). Springer Berlin Heidelberg. https://doi.org/10.1007/978-3-540-75957-7_9

Krützen, M., Mann, J., Heithaus, M. R., Connor, R. C., Bejder, L., \& Sherwin, W. B. (2005). Cultural transmission of tool use in bottlenose dolphins. Proceedings of the National Academy of Sciences of the United States of America, 102(25), 8939-8943. https://doi.org/10.1073/pnas.0500232102

Kuczaj, S., Tranel, K., Trone, M., \& Hill, H. (2001). Are animals capable of deception or empathy? Implications for animal consciousness and animal welfare. Animal Welfare, 10(Supplement 1), 161-173.

Kuczaj, S. A., II, Highfill, L., \& Byerly, H. (2012). The importance of considering context in the assessment of personality characteristics: evidence from ratings of dolphin personality. International Journal of Comparative Psychology, 25(4), 309-329.

Kumar, S., \& Hedges, S. B. (1998). A molecular timescale for vertebrate evolution. Nature, 392(6679), 917-920. https://doi.org/10.1038/31927

Lloyd, A. S., Martin, J. E., Bornett-Gauci, H. L. I., \& Wilkinson, R. G. (2008). Horse personality: Variation between breeds. Applied Animal Behaviour Science, 112(3), 369-383. https://doi.org/10.1016/j.applanim.2007.08.010

Lusseau, D., Wilson, B. E. N., Hammond, P. S., Grellier, K., Durban, J. W., Parsons, K. M., Barton, T. R., \& Thompson, P. M. (2006). Quantifying the influence of sociality on population structure in bottlenose dolphins. Journal of Animal Ecology, 75(1), 14-24. https://doi.org/10.1111/j.1365-2656.2005.01013.x 
803 MacCallum, R. C., Widaman, K. F., Zhang, S., \& Hong, S. (1999). Sample size in factor

804

805

806

807

808

809

810

811

812

813

814

815

816

817

818

819

820

821

822

823

824

825

826 analysis. Psychological Methods, 4(1), 84-99. https://doi.org/10.1037/1082$\underline{989 X .4 .1 .84}$

Matsuzawa, T. (2017). Horse cognition and behavior from the perspective of primatology. Primates, 58(4), 473-477. https://doi.org/10.1007/s10329-017-0632-9

McCort, W. D. (1984). Behavior of feral horses and ponies. Journal of Animal Science, 58(2), 493-499. https://doi.org/10.2527/jas1984.582493x

McCrae, R. R., \& Costa, P. T., Jr. (1989). The structure of interpersonal traits: Wiggins's circumplex and the five-factor model. Journal of Personality and Social Psychology, 56(4), 586-595. https://doi.org/10.1037/0022-3514.56.4.586

McCrae, R. R., Jang, K. L., Livesley, W. J., Riemann, R., \& Angleitner, A. (2001). Sources of structure: Genetic, environmental, and artifactual influences on the covariation of personality traits. Journal of Personality, 69(4), 511-535. https://doi.org/10.1111/1467-6494.694154

McCrae, R. R., Zonderman, A. B., Bond, M. H., Costa, P. T., Jr., \& Paunonen, S. V. (1996). Evaluating replicability of factors in the Revised NEO Personality Inventory: Confirmatory factor analysis versus Procrustes rotation. Journal of Personality and Social Psychology, 70(3), 552-566. https://doi.org/10.1037/0022-3514.70.3.552

Moreno, K., \& Acevedo-Gutiérrez, A. (2016). The social structure of Golfo Dulce bottlenose dolphins (Tursiops truncatus) and the influence of behavioural state. Royal Society Open Science, 3(8), Article 160010. https://doi.org/10.1098/rsos.160010

Moreno, K. R., Highfill, L., \& Kuczaj, I., Stan A. (2017). Does personality similarity in bottlenose dolphin pairs influence dyadic bond characteristics? International Journal of Comparative Psychology, 30, Article 33469. 
827

828

829

830

831

832

833

834

835

836

837

838

839

840

841

842

843

844

845

846

847

848

849

850

Morton, F. B., Lee, P. C., Buchanan-Smith, H. M., Brosnan, S. F., Thierry, B., Paukner, A., de Waal, F. B. M., Widness, J., Essler, J. L., \& Weiss, A. (2013). Personality structure in brown capuchin monkeys (Sapajus apella): Comparisons with chimpanzees (Pan troglodytes), orangutans (Pongo spp.), and rhesus macaques (Macaca mulatta). Journal of Comparative Psychology, 127(3), 282-298. https://doi.org/10.1037/a0031723

Mundfrom, D. J., Shaw, D. G., \& Ke, T. L. (2005). Minimum sample size recommendations for conducting factor analyses. International Journal of Testing, 5(2), 159-168. https://doi.org/10.1207/s15327574ijt0502_4

Nagell, K., Olguin, R. S., \& Tomasello, M. (1993). Processes of social learning in the tool use of chimpanzees (Pan troglodytes) and human children (Homo sapiens). Journal of Comparative Psychology, 107(2), 174-186. https://doi.org/10.1037/0735-

$\underline{7036.107 .2 .174}$

Nakahara, F., Komaba, M., Sato, R., Ikeda, H., Komaba, K., \& Kawakubo, A. (2017). Spontaneous prosocial choice by captive bottlenose dolphins, Tursiops truncatus. Behavioural Processes, 135, 8-11. https://doi.org/10.1016/j.beproc.2016.11.009

Neumann, C., Agil, M., Widdig, A., \& Engelhardt, A. (2013). Personality of wild male crested macaques (Macaca nigra). PLoS ONE, 8(8), Article e69383. https://doi.org/10.1371/journal.pone.0069383

R Core Team. (2020). R: A language and environment for statistical computing. In $\mathrm{R}$ Foundation for Statistical Computing. https://www.R-project.org/

Revelle, W. (2019). psych: Procedures for psychological, psychometric, and personality research. In (Version 1.9.12) Northwestern University. https://CRAN.Rproject.org/package $=$ psych 
851

852

853

854

855

856

857

858

859

860

861

862

863

864

865

866

867

868

869

870

871

872

873

Robbins, M. M. (1995). A demographic analysis of male life history and social structure of mountain gorillas. Behaviour, 132(1-2), 21-47. https://doi.org/10.1163/156853995X00261

Rouff, J. H., Sussman, R. W., \& Strube, M. J. (2005). Personality traits in captive lion-tailed macaques (Macaca silenus). American Journal of Primatology, 67(2), 177-198. https://doi.org/10.1002/ajp.20176

Rowe, D. C. (1982). Monozygotic twin cross-correlations as a validation of personality structure: A test of the semantic bias hypothesis. Journal of Personality and Social Psychology, 43(5), 1072-1079. https://doi.org/10.1037/0022-3514.43.5.1072

Russell, A. F., Brotherton, P. N. M., McIlrath, G. M., Sharpe, L. L., \& Clutton-Brock, T. H. (2003). Breeding success in cooperative meerkats: effects of helper number and maternal state. Behavioral Ecology, 14(4), 486-492. https://doi.org/10.1093/beheco/arg022

Schwarz, G. (1978). Estimating the dimension of a model. Annals of Statistics, 6(2), 461-464. https://doi.org/10.1214/aos/1176344136

Seltmann, M. W., Helle, S., Adams, M. J., Mar, K. U., \& Lahdenperä, M. (2018). Evaluating the personality structure of semi-captive Asian elephants living in their natural habitat. Royal Society Open Science, 5(2), Article 172026. https://doi.org/10.1098/rsos.172026

Serckx, A., Kühl, H. S., Beudels-Jamar, R. C., Poncin, P., Bastin, J.-F., \& Huynen, M.-C. (2015). Feeding ecology of bonobos living in forest-savannah mosaics: Diet seasonal variation and importance of fallback foods. American Journal of Primatology, 77(9), 948-962. https://doi.org/10.1002/ajp.22425 
874

875

876

877

878

879

880

881

882

883

884

885

886

887

888

889

890

891

892

893

894

895

896

897

898

Shane, S. H., Wells, R. S., \& Würsig, B. (1986). Ecology, behavior and social organization of the bottlenose dolphin: a review. Marine Mammal Science, 2(1), 34-63. https://doi.org/10.1111/j.1748-7692.1986.tb00026.x

Shrout, P. E., \& Fleiss, J. L. (1979). Intraclass correlations: Uses in assessing rater reliability. Psychological Bulletin, 86(2), 420-428. https://doi.org/10.1037/0033-2909.86.2.420

Shultz, S., Opie, C., \& Atkinson, Q. D. (2011). Stepwise evolution of stable sociality in primates. Nature, 479(7372), 219-222. https://doi.org/10.1038/nature10601

Stevenson-Hinde, J., \& Zunz, M. (1978). Subjective assessment of individual rhesus monkeys. Primates, 19(3), 473-482. https://doi.org/10.1007/BF02373309

Strickhouser, J. E., Zell, E., \& Krizan, Z. (2017). Does personality predict health and wellbeing? A metasynthesis. Health Psychology, 36(8), 797-810. https://doi.org/10.1037/hea0000475

Taylor, A. H., Hunt, G. R., \& Gray, R. D. (2012). Context-dependent tool use in New Caledonian crows. Biology Letters, 8(2), 205-207. https://doi.org/10.1098/rsbl.2011.0782

Thierry, B. (2000). Covariation of conflict management patterns across macaque species. In F. Aureli \& F. B. M. de Waal (Eds.), Natural conflict resolution (pp. 106-128). University of California Press.

Traupman, E. K., Smith, T. W., Uchino, B. N., Berg, C. A., Trobst, K. K., \& Costa, P. T., Jr. (2009). Interpersonal circumplex octant, control, and affiliation scales for the NEOPI-R. Personality and Individual Differences, 47(5), 457-463. https://doi.org/10.1016/j.paid.2009.04.018

Tsai, Y.-J. J., \& Mann, J. (2013). Dispersal, philopatry, and the role of fission-fusion dynamics in bottlenose dolphins. Marine Mammal Science, 29(2), 261-279. https://doi.org/10.1111/j.1748-7692.2011.00559.x 
899 Úbeda, Y., Ortín, S., St. Leger, J., Llorente, M., \& Almunia, J. (2019). Personality in captive killer whales (Orcinus orca): A rating approach based on the five-factor model.

901 Journal of Comparative Psychology, 133(2), 252-261. https://doi.org/10.1037/com0000146

903

904

905

906

907

908

909

910

911

912

913

914

915

916

917

918

919

920

921

Uher, J., Werner, C. S., \& Gosselt, K. (2013). From observations of individual behaviour to social representations of personality: Developmental pathways, attribution biases, and limitations of questionnaire methods. Journal of Research in Personality, 47(5), 647667. https://doi.org/10.1016/j.jrp.2013.03.006

van Schaik, C. P., Deaner, R. O., \& Merrill, M. Y. (1999, Jun). The conditions for tool use in primates: Implications for the evolution of material culture. Journal of Human Evolution, 36(6), 719-741. https://doi.org/10.1006/jhev.1999.0304

Vollrath, M. E., \& Torgersen, S. (2002). Who takes health risks? A probe into eight personality types. Personality and Individual Differences, 32(7), 1185-1197. https://doi.org/10.1016/S0191-8869(01)00080-0

von Rueden, C. (2020). Making and unmaking egalitarianism in small-scale human societies. Current Opinion in Psychology, 33, 167-171. https://doi.org/10.1016/j.copsyc.2019.07.037

Walker, J. L., Potter, C. W., \& Macko, S. A. (1999). The diets of modern and historic bottlenose dolphin populations reflected through stable isotopes. Marine Mammal Science, 15(2), 335-350. https://doi.org/10.1111/j.1748-7692.1999.tb00805.x

Wallen, M. M., Patterson, E. M., Krzyszczyk, E., \& Mann, J. (2016). The ecological costs to females in a system with allied sexual coercion. Animal Behaviour, 115, 227-236. https://doi.org/10.1016/j.anbehav.2016.02.018 
922 Weiss, A. (2017). Exploring factor space (and other adventures) with the Hominoid

923

924

925

926

927

928

929

930

931

932

933

934

935

936

937

938

939

940

941

942

943

944

945 Personality Questionnaire. In J. Vonk, A. Weiss, \& S. Kuczaj (Eds.), Personality in Nonhuman Animals (pp. 19-38). Springer. https://doi.org/10.1007/978-3-319-59300-5

Weiss, A. (2018). Personality traits: A view from the animal kingdom. Journal of Personality, 86(1), 12-22. https://doi.org/10.1111/jopy.12310

Weiss, A., \& Adams, M. J. (2013). Differential behavioral ecology. In C. Carere \& D. Maestripieri (Eds.), Animal personalities: Behavior, physiology and evolution (pp. 96123). University of Chicago Press.

Weiss, A., Adams, M. J., Widdig, A., \& Gerald, M. S. (2011). Rhesus macaques (Macaca mulatta) as living fossils of hominoid personality and subjective well-being. Journal of Comparative Psychology, 125(1), 72-83. https://doi.org/10.1037/a0021187

Weiss, A., Inoue-Murayama, M., Hong, K.-W., Inoue, E., Udono, S., Ochiai, T., Matsuzawa, T., Hirata, S., \& King, J. E. (2009). Assessing chimpanzee personality and subjective well-being in Japan. American Journal of Primatology, 71(4), 283-292. https://doi.org/10.1002/ajp.20649

Weiss, A., King, J. E., \& Perkins, L. (2006). Personality and subjective well-being in orangutans (Pongo pygmaeus and Pongo abelii). Journal of Personality and Social Psychology, 90(3), 501-511. https://doi.org/10.1037/0022-3514.90.3.501

Weiss, A., Staes, N., Pereboom, J. J. M., Inoue-Murayama, M., Stevens, J. M. G., \& Eens, M. (2015). Personality in bonobos. Psychological Science, 26(9), 1430-1439. https://doi.org/10.1177/0956797615589933

Weiss, A., Yokoyama, C., Hayashi, T., \& Inoue-Murayama, M. (2020). Personality, subjective well-being, and the serotonin 1a receptor gene in common marmosets (Callithrix jacchus). bioRxiv. https://doi.org/10.1101/2020.04.30.069773 
946 Wheeler, B. C. (2009). Monkeys crying wolf? Tufted capuchin monkeys use anti-predator

947

948

949

950

951

952

953

954

955

956

957

958

959

960

961

962

963

964 calls to usurp resources from conspecifics. Proceedings of the Royal Society B: Biological Sciences, 276(1669), 3013-3018. https://doi.org/10.1098/rspb.2009.0544

Whiten, A., \& van de Waal, E. (2018). The pervasive role of social learning in primate lifetime development. Behavioral Ecology and Sociobiology, 72(5), Article 80. https://doi.org/10.1007/s00265-018-2489-3

Wittig, R. M., \& Boesch, C. (2003). Food competition and linear dominance hierarchy among female chimpanzees of the Taï National Park. International Journal of Primatology, 24(4), 847-867. https://doi.org/10.1023/A:1024632923180

Yamagata, S., Suzuki, A., Ando, J., Ono, Y., Kijima, N., Yoshimura, K., Ostendorf, F., Angleitner, A., Riemann, R., Spinath, F. M., Livesley, W. J., \& Jang, K. L. (2006). Is the genetic structure of human personality universal? A cross-cultural twin study from North America, Europe, and Asia. Journal of Personality and Social Psychology, 90(6), 987-998. https://doi.org/10.1037/0022-3514.90.6.987

Yamamoto, C., Morisaka, T., Furuta, K., Ishibashi, T., Yoshida, A., Taki, M., Mori, Y., \& Amano, M. (2015). Post-conflict affiliation as conflict management in captive bottlenose dolphins (Tursiops truncatus). Scientific Reports, 5(1), Article 14275. https://doi.org/10.1038/srep14275 